Received: 16 July 2018

Accepted: 7 March 2019

Published online: 25 March 2019

CIENTIFIC REP

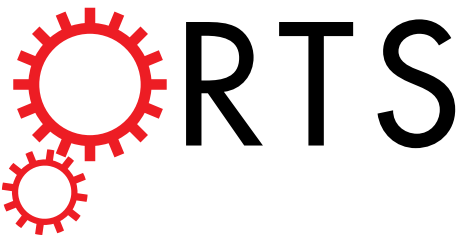

\title{
OPEN
}

\section{The Gene ANTHER DEHISCENCE REPRESSOR (ADR) Controls Male Fertility by Suppressing the ROS Accumulation and Anther Cell Wall Thickening in Arabidopsis}

\author{
Shu-Yu Dai ${ }^{1}$, Wei-Han Hsu ${ }^{1}$ \& Chang-Hsien Yang ${ }^{1,2}$
}

Male sterility in plants is caused by various stimuli such as hormone changes, stress, cytoplasmic alterations and nuclear gene mutations. The gene ANTHER DEHISCENCE REPRESSOR (ADR), which is involved in regulating male sterility in Arabidopsis, was functionally analyzed in this study. In ADR::GUS flowers, strong GUS activity was detected in the anthers of young flower buds but was low in mature flowers. ADR + GFP fusion proteins, which can be modified by N-myristoylation, were targeted to peroxisomes. Ectopic expression of $A D R$ in transgenic Arabidopsis plants resulted in male sterility due to anther indehiscence. The defect in anther dehiscence in $35 \mathrm{~S}:: A D R$ flowers is due to the reduction of ROS accumulation, alteration of the secondary thickening in the anther endothecium and suppression of the expression of $N S T 1$ and $N S T 2$, which are required for anther dehiscence through regulation of secondary wall thickening in anther endothecial cells. This defect could be rescued by external application of hydrogen peroxide $\left(\mathrm{H}_{2} \mathrm{O}_{2}\right)$. These results demonstrated that ADR must be $\mathrm{N}$-myristoylated and targeted to the peroxisome during the early stages of flower development to negatively regulate anther dehiscence by suppressing ROS accumulation and NST1/NST2 expression.

Anther dehiscence is an important process in mature stamens. In this process, lignin accumulation in the endothecium of anthers enables secondary wall thickening. Subsequently, septum and stomium lysis completes dehiscence ${ }^{1-6}$.

The expansion of the endothecium provides an internal directed force for anther dehiscence, causing breakdown of the stomium. Then, desiccation of the epidermis causes differential shrinkage of thickened and unthickened parts of the cell wall, resulting in an outwardly bending force that leads to the retraction of the anther wall and the complete opening of the stomium ${ }^{7-9}$. Lignin is the major compound involved in secondary wall thickening in anthers, and its polymerization is dependent on hydrogen peroxide $\left(\mathrm{H}_{2} \mathrm{O}_{2}\right)$ levels ${ }^{10}$ which is the major ROS form in plant cells and the substrate for peroxidase in catalyzing lignin polymerization ${ }^{11-14}$. The final polymerization steps of lignin biosynthesis occur after the activation of monolignols to free radicals, which is mediated by peroxidase $+\mathrm{H}_{2} \mathrm{O}_{2}$ and/or oxidase (laccase) $+\mathrm{O}_{2}$, followed by non-enzymatic coupling of monolignol radicals to form the polymer lignin ${ }^{11-15}$. Interestingly, $\mathrm{H}_{2} \mathrm{O}_{2}$ also plays an important role as a signal in activating transcription of lignin biosynthesis enzyme such as peroxidases ${ }^{16}$. It has been reported that catalases (CATs) are the other major $\mathrm{H}_{2} \mathrm{O}_{2}$-scavenging enzymes which are located in peroxisomes ${ }^{17}$. In a previous study, the NAC transcription factors NAC SECONDARY WALL THICKENING PROMOTING FACTOR1 (NST1) and NST2 were reported to regulate lignin synthesis of anther secondary walls ${ }^{18}$. Double mutations in NST1 and NST2 caused sterility due to anther indehiscence.

Although it is well established that the $\mathrm{H}_{2} \mathrm{O}_{2}$ level in the anther endothecium is strongly correlated with the lignin polymerization and anther dehiscence, the mechanisms regulate $\mathrm{H}_{2} \mathrm{O}_{2}$ level in the anther still remain to be investigated. In cells, the $\mathrm{H}_{2} \mathrm{O}_{2}$ can be accumulated in organelles such as peroxisomes, which are single

${ }^{1}$ Institute of Biotechnology, National Chung Hsing University, Taichung, Taiwan, 40227, ROC. ${ }^{2}$ Advanced Plant Biotechnology Center, National Chung Hsing University, Taichung, Taiwan, 40227, ROC. Correspondence and requests for materials should be addressed to C.-H.Y. (email: chyang@dragon.nchu.edu.tw) 
membrane-bound organelles with diverse metabolic functions ${ }^{19,20}$. In association with ROS production, peroxisome targeted PAO (polyamine oxidase) has been reported to regulate pollen tube elongation ${ }^{21}$. A mutation in the peroxisomal membrane protein DAYU impairs pollen maturation and germination ${ }^{22}$. However, the association between anther dehiscence and peroxisomes remains unclear. Therefore, it is interesting to explore the mechanisms or factors that regulate or affect $\mathrm{H}_{2} \mathrm{O}_{2}$ accumulation in peroxisomes.

To explore the association between $\mathrm{H}_{2} \mathrm{O}_{2}$-regulated anther dehiscence and peroxisomes, a novel ANTHER DEHISCENCE REPRESSOR (ADR) gene (At4g13540), which is potentially N-myristoylated and targeted to peroxisomes, was cloned from Arabidopsis and analyzed. The ADR protein contains a predicted conserved recognition site (GGSTSKD) for N-myristoylase ${ }^{23}$ at the N-terminus of the protein. It has been reported that the $\mathrm{N}$-terminal octapeptide of ADR can be myristoylated by AtNMTs (N-myristoyltransferase $)^{23}$. ADR also contains a binding site for a peroxisomal targeting signal (PTS) in the middle of the protein, which indicates that ADR is likely targeted to the peroxisomes. The PTS binding site is critical for protein targeting and binding to peroxisomal matrix proteins (Pex5 and Pex7) or peroxisomal membrane proteins (Pex19) and thus allows the peroxisome entry or peroxisomal membrane association ${ }^{24}$. N-myristoylation involves the addition of the saturated C:14 fatty acid myristate to the $\mathrm{N}$-terminus of proteins and affects the membrane binding properties of proteins ${ }^{23,25}$. A mutation in the myristoylation domain did not interfere with peroxisomal targeting but disrupted the membrane association of proteins because it prevented the addition of the myristoyl group that is also essential for membrane association. Based on these observations, proteins lacking a myristoyl group can still bind to Pex through the PTS binding site and target to the peroxisome, but they cannot stably associate with the peroxisomal membrane. In this study, we demonstrated that ADR proteins are likely modified by N-myristoylation and targeted to peroxisomes. We showed that ectopically expressing $A D R$ causes male sterility of the flowers due to anther indehiscence. We also found that $A D R$ functions to reduce ROS accumulation and suppresses the expression of NST1 and NST2. Thus, we propose a model in which ADR is myristoylated and negatively regulates anther dehiscence by promoting ROS scavenging in the peroxisome, which affect lignin polymerization and stomium rupture in Arabidopsis.

\section{Results}

Isolation of $A D R$ CDNA from Arabidopsis. ADR contains 2 exons and 1 intron and encodes a protein of 210 amino acids (Fig. S1). A predicted conserved recognition site (GGSTSKD) for N-myristoylase ${ }^{23}$ and several basic residues reported to stabilize membrane binding ${ }^{26}$ were identified at the $\mathrm{N}$-terminus of the ADR proteins (Fig. S1). A binding site for a peroxisomal targeting signal (PTS) predicted using the PTSs Target Signal Predictor (http://216.92.14.62/Target_signal.php) was also found in the middle of the protein (Fig. S1). In contrast, no MTS (mitochondria targeting sequence) was identified in ADR using the prediction tool MitoFates (http://mitf. cbrc.jp/MitoFates/cgi-bin/top.cgi). The ADR protein showed $68 \%$ identity and $78 \%$ similarity to the most closely related ADR-like protein, At3g23930 (Fig. S1). In their N-myristoylase sites, 95\% of the amino acids are identical (Fig. S1).

RT-PCR analysis of $A D R$ transcripts and detection of $A D R$ expression by analyzing ADR::GUS transgenic Arabidopsis plants. Reverse transcription PCR (RT-PCR) was performed to determine the relative transcript abundance of $A D R$ at different developmental stages and in various organs of Arabidopsis. $A D R$ expression was not detected in early seedling development (Fig. 1A). The transcript level of $A D R$ was strongly detected in flowers and weakly detected in the roots, stem and siliques, but $A D R$ transcripts were absent in the leaves of mature plants (Fig. 1A). When the expression of $A D R$ in flowers at different developmental stages was further analyzed, significantly higher expression of $A D R$ was observed in early development stages (stages 8-11) than in late flower development stages (after stage 12; Fig. 1B).

To further analyze the expression pattern of the ADR gene in flowers, a construct (ADR::GUS) was generated and transformed into Arabidopsis; twelve independent ADR::GUS plants were obtained. GUS activity in the ADR::GUS flowers was strongly detected in sepals but was relatively weakly detected in petals and carpels during early and late flower development (Fig. 1C,E). In the stamen, GUS activity was strongly detected in anthers during early flower development stages (before stage 10; Fig. 1C,D), but its expression was almost undetectable in anthers during late developmental stages (Fig. 1E,F).

$A D R$ needs to targeted to peroxisomes to perform its function. It has been shown that the $\mathrm{N}$-terminus of ADR can be myristoylated by an in vitro myristoylation assay after the first eight residues of the $\mathrm{N}$-terminal peptide sequence recognized by $N$-myristoyltransferase ${ }^{23}$. Because $\mathrm{N}$-myristoylation is known to affect the membrane-binding properties of proteins ${ }^{25}$, an Agrobacterium infiltration-mediated transient expression assay was performed to validate the membrane association properties of ADR. The cDNA of $A D R$ fused with GFP driven by the cauliflower mosaic virus (CaMV) $35 \mathrm{~S}$ promoter $(A D R+G F P)$ were transformed into Agrobacterium and infiltrated into the leaf epidermis of Nicotiana benthamiana. The results showed that $\mathrm{ADR}+\mathrm{GFP}$ fusion proteins mainly accumulated in organelle-like structures (Fig. 2A,B) which may be the peroxisomes since ADR contains a binding site for a peroxisomal targeting signal (PTS) as described above (Fig. S1). To examine that the organelle-like structures were peroxisomes, a construct of CATALASE 3 (CAT3) fused to mORANGE2 (CAT3 + mORG2) was co-transformed with ADR + GFP into Agrobacterium and infiltrated into the leaf epidermis of $N$. benthamiana. It has been shown that CAT3 could localize to the peroxisomes ${ }^{27}$ (Fig. 2C,D). Confocal images showed that ADR + GFP co-localized with CAT3 + mORG2 (Fig. 2E,F), indicating that myristoylated ADR is likely associated with peroxisomes. Both ADR + GFP and CAT3 + mORG2 were also detected in the nucleus (Fig. 2A,C,E). Because it has been reported that the maximum protein size that can diffuse freely through the nuclear pore is larger than $60 \mathrm{kDa}^{28}$, the diffusion of these two proteins (both are smaller than $60 \mathrm{kD}$ ) into the nucleus may be due to the over-expression of high amounts of the proteins in these cells. 
A
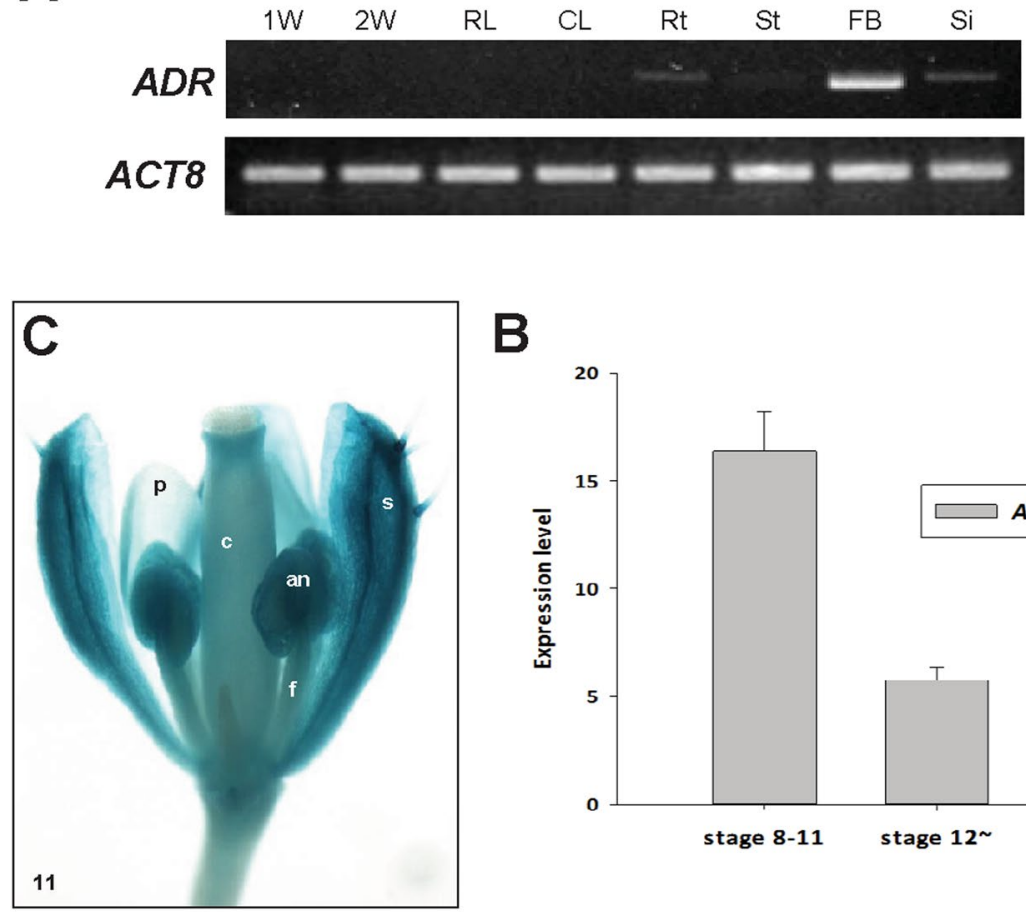

B
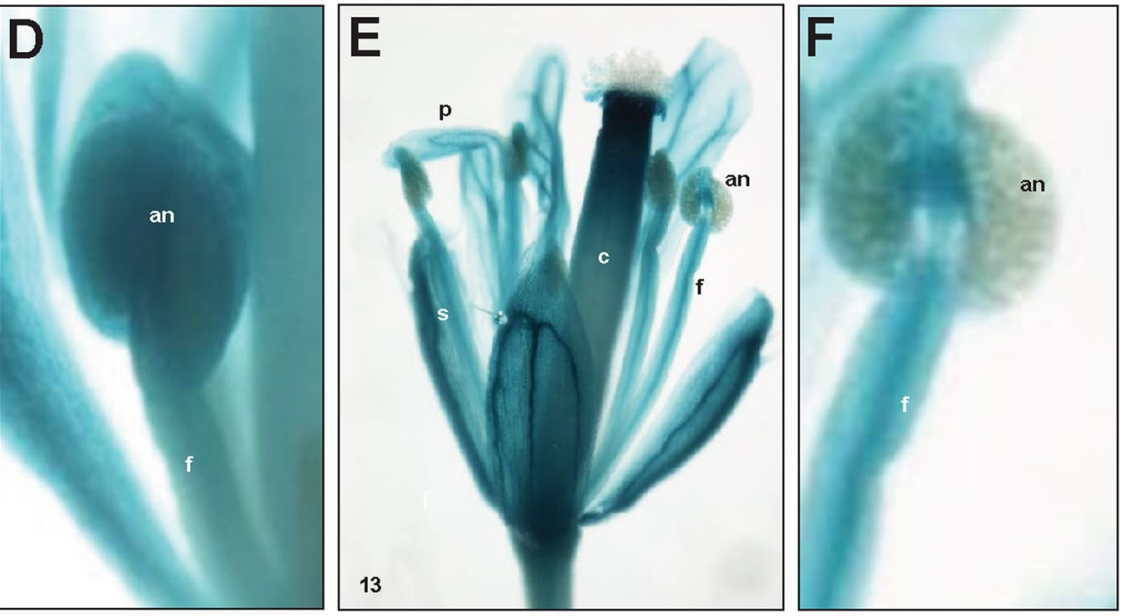

Figure 1. Analysis of $A D R$ expression in different Arabidopsis organs and GUS staining patterns in ADR::GUS Arabidopsis flowers. (A) The detection of ADR expression in different Arabidopsis organs. The mRNA levels were determined by RT-PCR. Total RNA was isolated from 1-week-old seedlings (1W), 2-week-old seedlings $(2 \mathrm{~W})$, rosette leaves $(\mathrm{RL})$, cauline leaves $(\mathrm{CL})$, roots $(\mathrm{Rt})$, stems (St), floral buds (FB) and siliques (Si). The Arabidopsis ACTIN8 (ACT8) gene was used as internal controls. The grouping of two gels (ADR and ACT8) was cropped from two different original gels in Fig. S4. (B) The detection of ADR expression in wild-type flowers at two different developmental stages $(8-11,>12)$. The mRNA levels were determined by real-time quantitative PCR. (C) In stage 11 of ADR::GUS young floral buds, GUS activity was strongly detected in the sepals (s) and anthers (an) of stamens but relatively weakly detected in the petals (p), carpels (c) and filaments (f) of stamens. (D) Close-up of the anther (an) from (C). (E) In stage 13 of ADR::GUS mature flowers, GUS was strongly detected in sepals (s), petals (p) and carpels (c). In the stamen, GUS activity was detected in the filaments (f) but was absent in the anthers (an) of stamens. (F) Close-up of the anther (an) from (E).

It has been reported that some proteins containing MTS (mitochondria targeting sequence) are targeted to the mitochondria after $\mathrm{N}$-myristoylation ${ }^{29}$. To further confirm the localization of ADR is not in other organelles such as mitochondria, a construct of the mitochondria marker $M T$ fused to $m$ Cherry $(M T+R K)$ was co-transformed with $A D R+G F P$ into Agrobacterium and infiltrated into the leaf epidermis of $N$. benthamiana. Confocal images showed that ADR + GFP (Fig. 3A,B,E,F) did not co-localize with MT + RK (Fig. 3C-F), indicating that myristoylated ADR is not associated with mitochondria. 

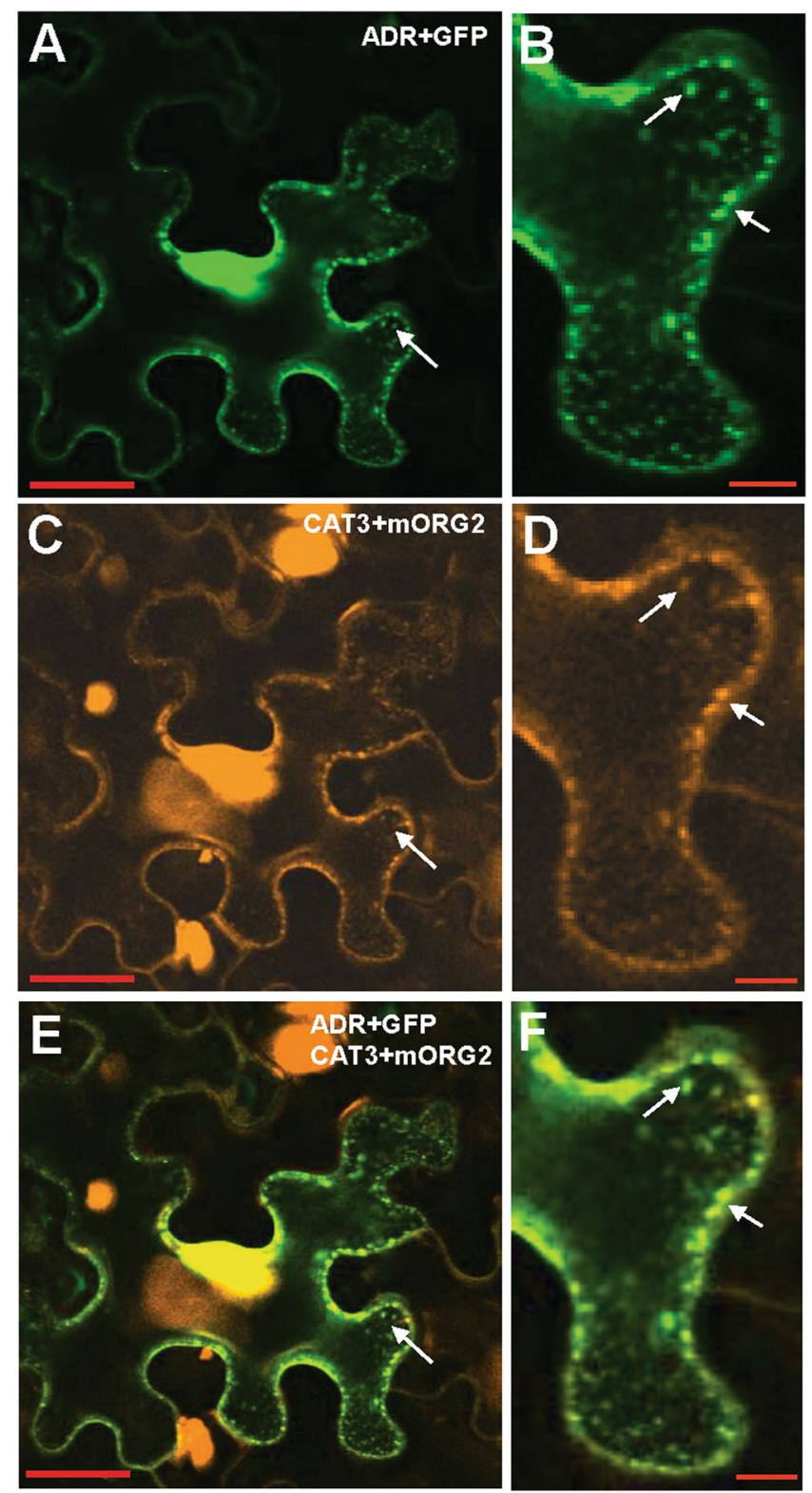

Figure 2. Transient expression of ADR + GFP and CAT3 + mORG2 in tobacco cells. (A-D) Agrobacteriummediated transient expression of $\operatorname{ADR}+\operatorname{GFP}(\mathbf{A}, \mathbf{B})$ and CAT3 + mORG2 $(\mathbf{C}, \mathbf{D})$ in epidermal cells of $N$. benthamiana. ADR + GFP fusion protein accumulated in organelle-like structures (arrowed in $\mathbf{A}, \mathbf{B}$ ) that were highly similar to peroxisomes, where CAT3 + mORG2 were localized (arrowed in C,D). (E,F) A merged fluorescence image of (A and C) in (E); (B and $\mathbf{D})$ in (F) showed the co-localization of ADR + GFP and CAT3 + mORG2 (green-yellow color) in peroxisomes (arrowed). (B,D and F) are the close-up images from $(\mathbf{A}, \mathbf{C}$ and $\mathbf{E})$, respectively. Scale bars: $30 \mu \mathrm{m}$ in $(\mathbf{A}, \mathbf{C}$ and $\mathbf{E})$ and $5 \mu \mathrm{m}$ in $(\mathbf{B}, \mathbf{D}$ and $\mathbf{F})$.

Ectopic expression of $A D R$ causes plant sterility due to anther indehiscence. To investigate the function of the $A D R$ gene, the cDNA of the $A D R$ gene driven by the cauliflower mosaic virus (CaMV) $35 \mathrm{~S}$ promoter (35S::ADR) was transformed into Arabidopsis. A total of sixteen 35S::ADR transgenic Arabidopsis plants showing similar abnormal phenotypes were obtained. When the inflorescence was examined, a sterile flower phenotype with the siliques failing to elongate during late development was observed in these $35 \mathrm{~S}:: A D R$ transgenic plants (Fig. $4 \mathrm{~A}-\mathrm{C}$ ). The severity of the sterile phenotype in the $35 \mathrm{~S}:: A D R$ plants was correlated with the $A D R$ expression level (Fig. 4C,D).

When the 35S::ADR flowers (Fig. 4E) were examined, they were similar to wild-type flowers (Fig. 4F), opening normally and producing normal sepals, petals and carpels with fully developed stigmatic papillae. The anthers of the 35S::ADR flowers were indehiscent at all stages of flower development (Fig. 4E,G). In contrast, wild-type anthers were dehiscent, and pollen released after stage 12 of flower development (Fig. 4F,H). The 35S::ADR flowers with severe phenotypes were sterile and unable to set seed due to the indehiscence of anthers throughout flower development (Fig. 4C). To further examine pollen viability, Alexander's stain, which can distinguish viable pollen 

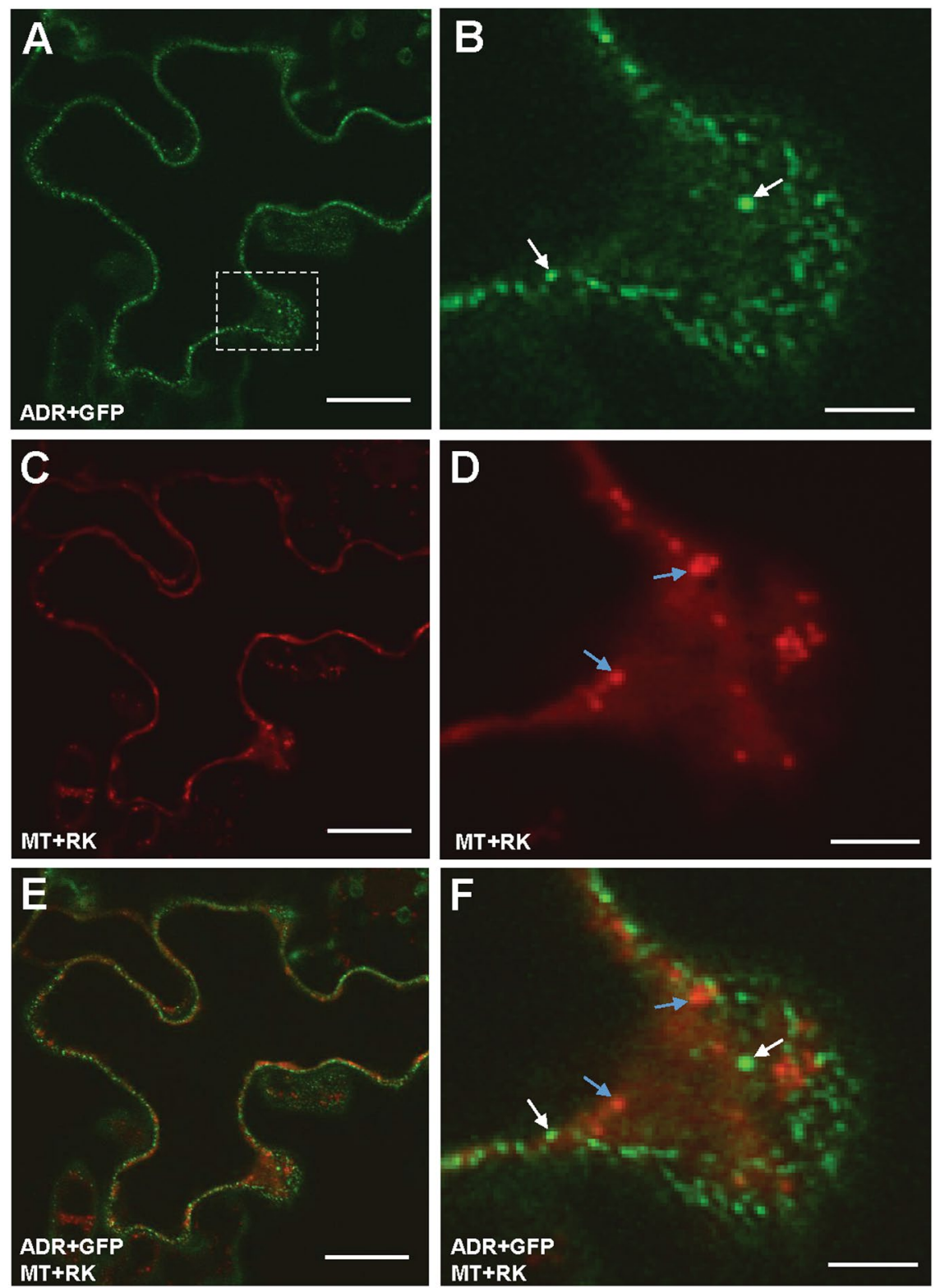

Figure 3. Transient expression of $A D R+G F P$ and $M T+R K$ in tobacco cells. (A-D) Agrobacteriummediated transient expression of $\operatorname{ADR}+\operatorname{GFP}(\mathbf{A}, \mathbf{B})$ and MT + RK $(\mathbf{C}, \mathbf{D})$ in epidermal cells of $N$. benthamiana. $\mathrm{ADR}+\mathrm{GFP}$ fusion protein accumulated in organelle-like structures (white arrows in B), whereas MT + RK was localized in mitochondria (blue arrows in D). (E,F) A merged fluorescence image of (A and $\mathbf{C})$ in (E); (B and D) in (F) showing the different localization of ADR + GFP (white arrows in $\mathbf{F}$ ) and MT + RK (blue arrows in $\mathbf{F}$ ). $(\mathbf{B}, \mathbf{D}$ and $\mathbf{F})$ are close-up images (boxed) from (A,C and $\mathbf{E})$, respectively. Scale bars: $20 \mu \mathrm{m}$ in $(\mathbf{A}, \mathbf{C}$ and $\mathbf{E})$ and 5 $\mu \mathrm{m}$ in $(\mathbf{B}, \mathbf{D}$ and $\mathbf{F})$.

from nonviable pollen ${ }^{30}$, was applied. Normal viability (dark blue staining), similar to that of wild-type pollen (Fig. 5A), was observed in the 35S::ADR pollen (Fig. 5B). When further examined by SEM, the pollen grains from wild-type anthers and $35 S:: A D R$ indehiscent anthers exhibited a similar egg shape, $30 \times 5$ micrometers in size (Fig. 5C,D). These results indicate that the pollen produced in the 35S::ADR flowers was still functional.

To examine pistil function, 35S::ADF stigmas were manually pollinated with pollen from wild-type flowers. Elongated and fully developed siliques (Fig. 5E,F) with normal seed development (Fig. 5G) were observed. This result confirms that the sterility of the $35 \mathrm{~S}:: A D R$ flowers is due to the indehiscence of the anther.

To further determine the role of $A D R$ in regulating anther dehiscence, an $A D R$ loss-of-function T-DNA insertion line, SALK_072305 (containing an insertion in the 5' promoter region) (Fig. S2A), was analyzed. The result indicated that these $A D R$ mutants were phenotypically indistinguishable from wild-type plants in both vegetative and reproductive development (Fig. S2B). Furthermore, the anthers in these ADR mutants were dehiscent normally (Fig. S2C,D) similar to that in wild-type plants. This finding indicates a possible functional redundancy 

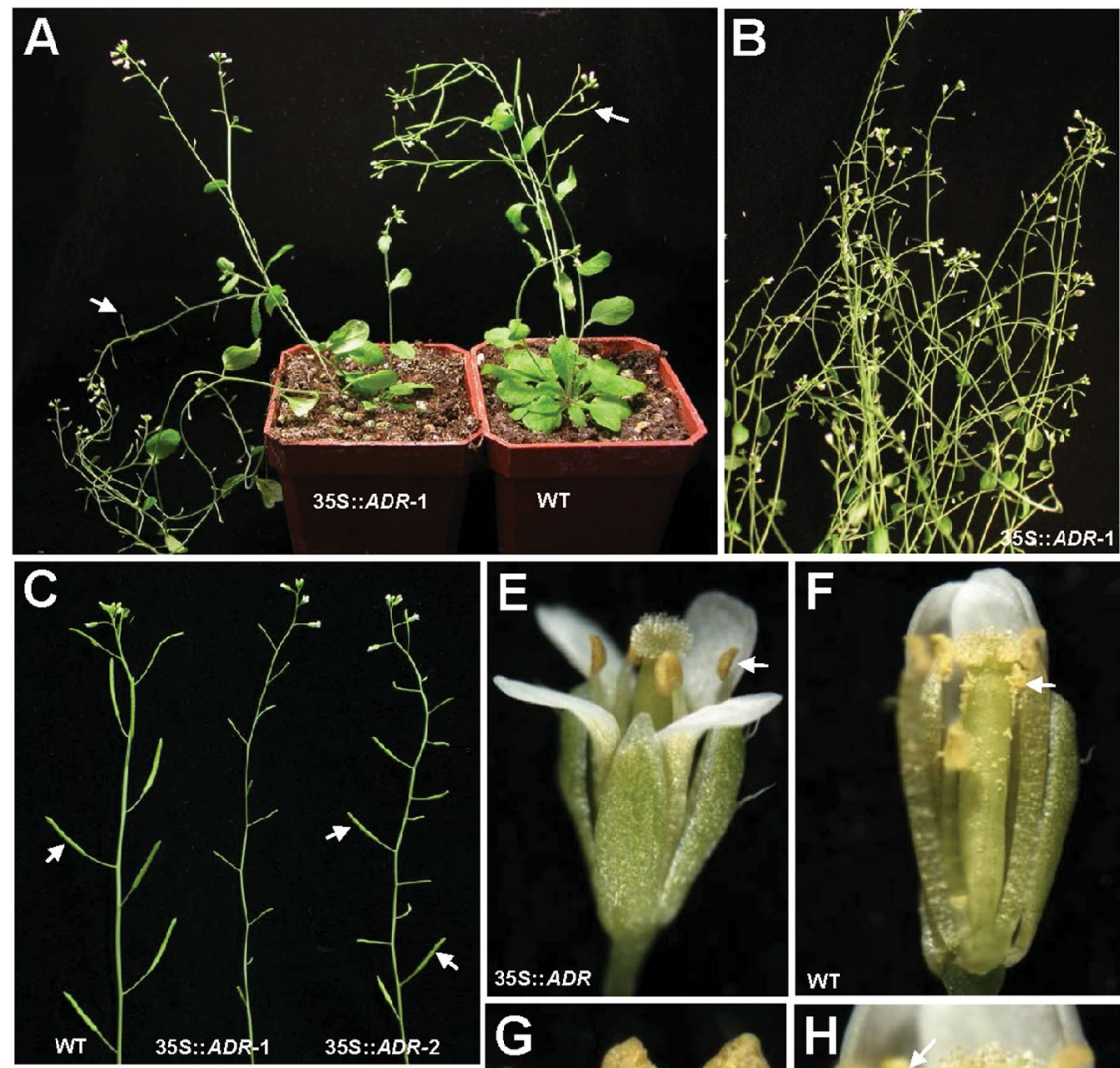

D
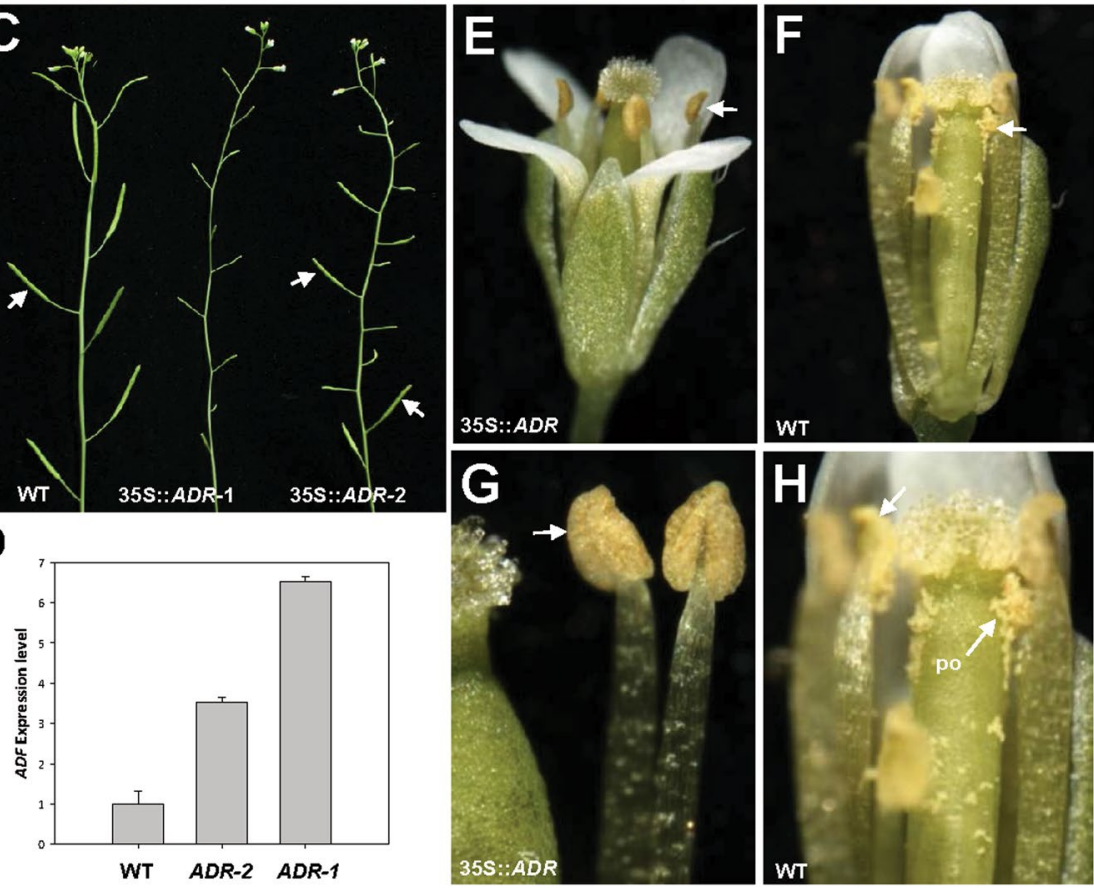

Figure 4. Phenotypic analysis and the detection of gene expression in Arabidopsis plants ectopically expressing $A D R$. (A) A severe 44-day-old 35S::ADR plant (35S::ADR-1, left) was sterile and produced short siliques (arrowed), whereas wild-type plants (WT, right) produced long, well-developed siliques (arrowed). (B) Close-up of the inflorescences from a severe 35S::ADR (35S::ADR-1) plant during the late developmental stage. (C) Inflorescences from a severe 35S::ADR transgenic line (35S::ADR-1, middle) that showed sterility, a medium-severe 35S::ADR transgenic line (35S::ADR-2, right) that showed partial sterility and some partially elongated siliques (arrowed), and one wild-type plant (WT, left) with fully elongated siliques (arrowed). (D) Detection of gene expression in 35S::ADR transgenic Arabidopsis. mRNA accumulation for $A D R$ was determined by real-time quantitative PCR. Total RNA isolated from flower buds before stage 12 of one wildtype plant (WT), one severe 35S::ADR-1 plant (ADR-1) and one medium-severe 35S::ADR-2 plant (ADR-2) was used as templates. The transcript levels of $A D R$ were determined using three replicates and were normalized against that of UBQ10. Gene expression levels in 35S::ADR plants are presented relative to that of the wild-type plants, which was set at 1. Error bars represent the standard deviation. Each experiment was repeated twice and resulted in similar results. $(\mathbf{E}, \mathbf{F})$ Indehiscent anthers (arrowed) were observed in 35S::ADR plants (E) compared to wild-type plants, which showed normal anther dehiscence and pollen (arrowed) release (F). (G) Close-up of the 35S::ADR indehiscent anthers (arrowed) from (E). (H) Close-up of the wild-type dehiscent anthers (arrowed) with released pollen (po) from (F).

between $A D R$ and other unknown genes. Further analysis indicated that the expression of $A D R$ in these T-DNA insertion mutants was significantly reduced (Fig. S2E).

Ectopic expression of $A D R$-Gly resulted in normal fertility. To confirm the myristoylated ADR was associated with the sterile phenotype observed in $35 \mathrm{~S}:: A D R$ plants, a mutated ADR that lacks the $\mathrm{N}$-terminal myristoylation site Gly (35S::ADR-Gly) was transformed into Arabidopsis, and the phenotype was analyzed. Unlike 35S::ADR plants, 35S::ADR-Gly plants showed normal fertility, similar to wild-type (Fig. S3A,B). 

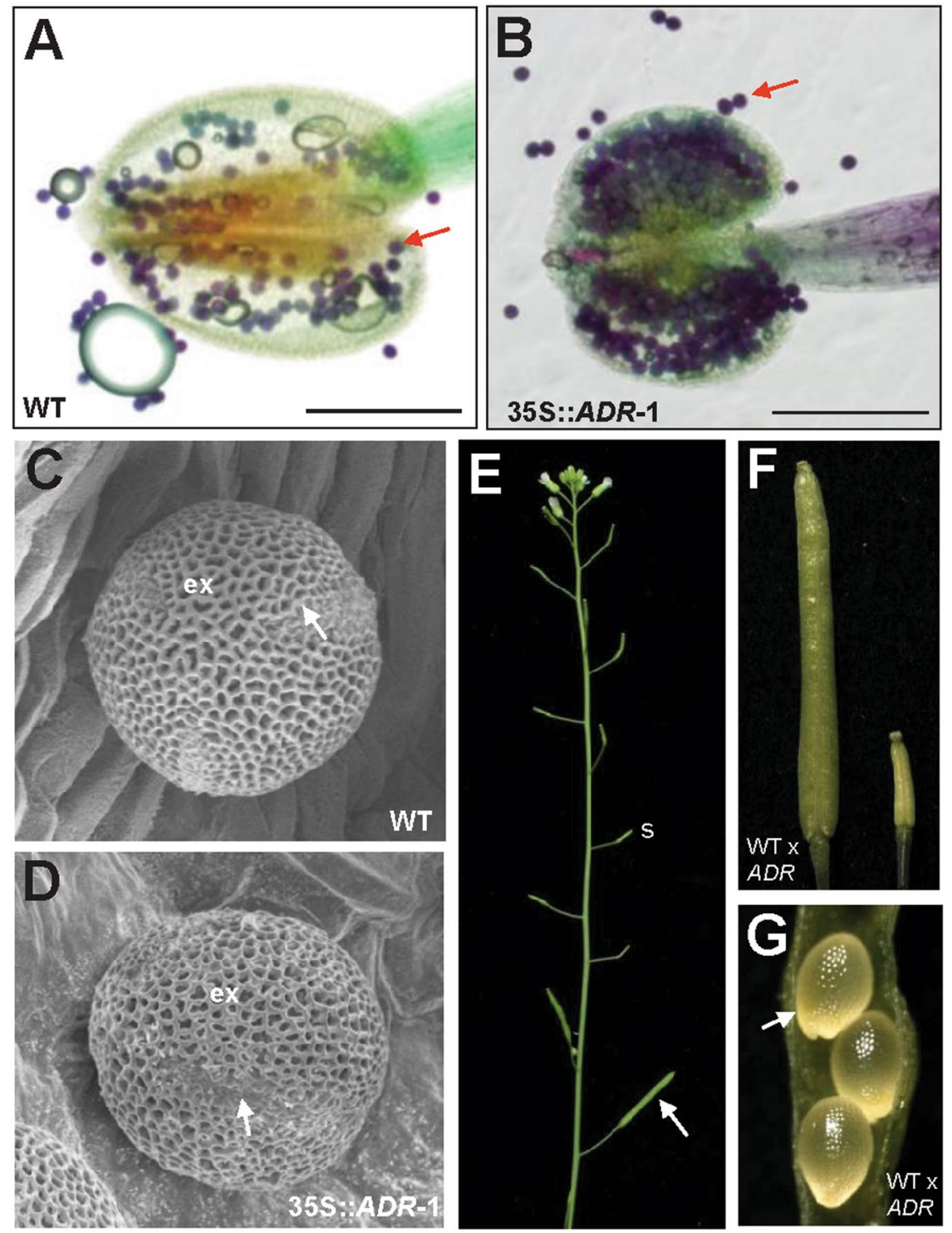

Figure 5. Alexander's staining and scanning electron microscopy of pollen produced in wild-type and $35 S:: A D R$ flowers and cross-pollination of wild-type pollen to $35 \mathrm{~S}:: A D R$ plants. $(\mathbf{A}, \mathbf{B})$ Pollen grains with normal viability (arrowed, stained dark purplish red) were observed in both the wild-type (A) and severe 35S::ADR anthers (B). (C,D) Close-up of the egg-shaped wild-type (C) and severe 35S::ADR (D) pollen grains. Colpi (arrowed) and outer exine (ex) with a typical irregular wall structure were observed on the surface of pollen. (E) The 35S::ADR flower that was manually pollinated with wild-type pollen developed well-elongated siliques (arrowed), whereas short siliques (s) developed without manual pollination. (F) Close-up of a well-elongated silique (WT x 35S::ADR) (left) and a short silique (right) from (E). (G) 35S::ADR ovules developed into normal embryos (arrowed) after manual pollination with wild-type (WT x 35S::ADR) pollen grains.

Elongated and fully developed siliques that clearly differed from those of 35S::ADR flowers (Fig. S3A,B,D) were observed in 35S::ADR-Gly inflorescence (Fig. S3B,C). Upon further examination, the anthers of 35S::ADR-Gly plants, which were normal dehiscent anthers that were distinct from those of $35 \mathrm{~S}:: A D R$ plants (Fig. S3E,F), were observed (Fig. S3G,H). These results indicated that the sterile phenotype of 35S::ADR plants is correlated with the myristoylation.

The secondary wall thickening was affected in 35S::ADR anthers. In the process of anther dehiscence, lignification enables the secondary wall thickening in endothecial cells of the anther ${ }^{15}$, it is possible that the lignification of the endothecial cells of the $35 S:: A D R$ anthers is affected.

To further analyze the cellular basis for anther dehiscence and to examine the formation of secondary wall thickness, lignin staining with auramine $\mathrm{O}$ was performed on the endothecium of developing anthers in both $35 S:: A D R$ and wild-type plants. The result indicated that secondary thickening occurs in the endothecium before anther dehiscence, and the surrounding cell layers of the anther did not undergo secondary thickening during 

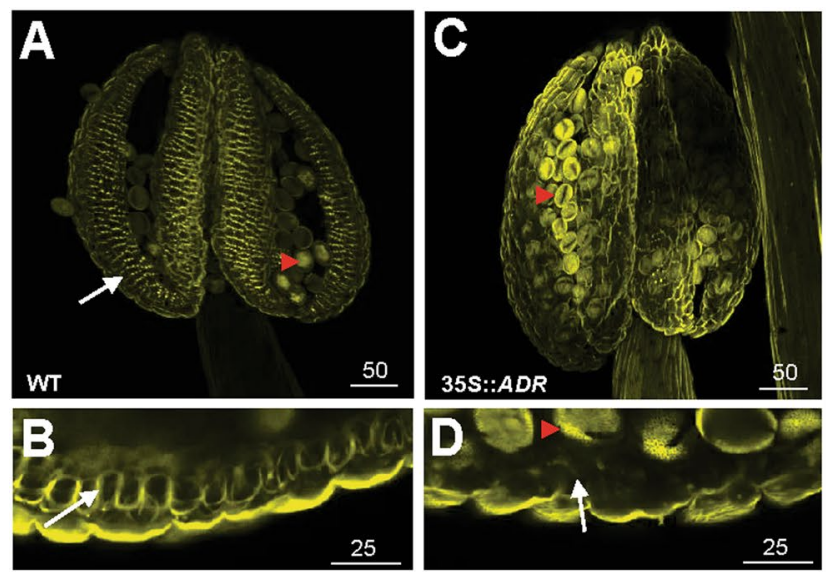

E
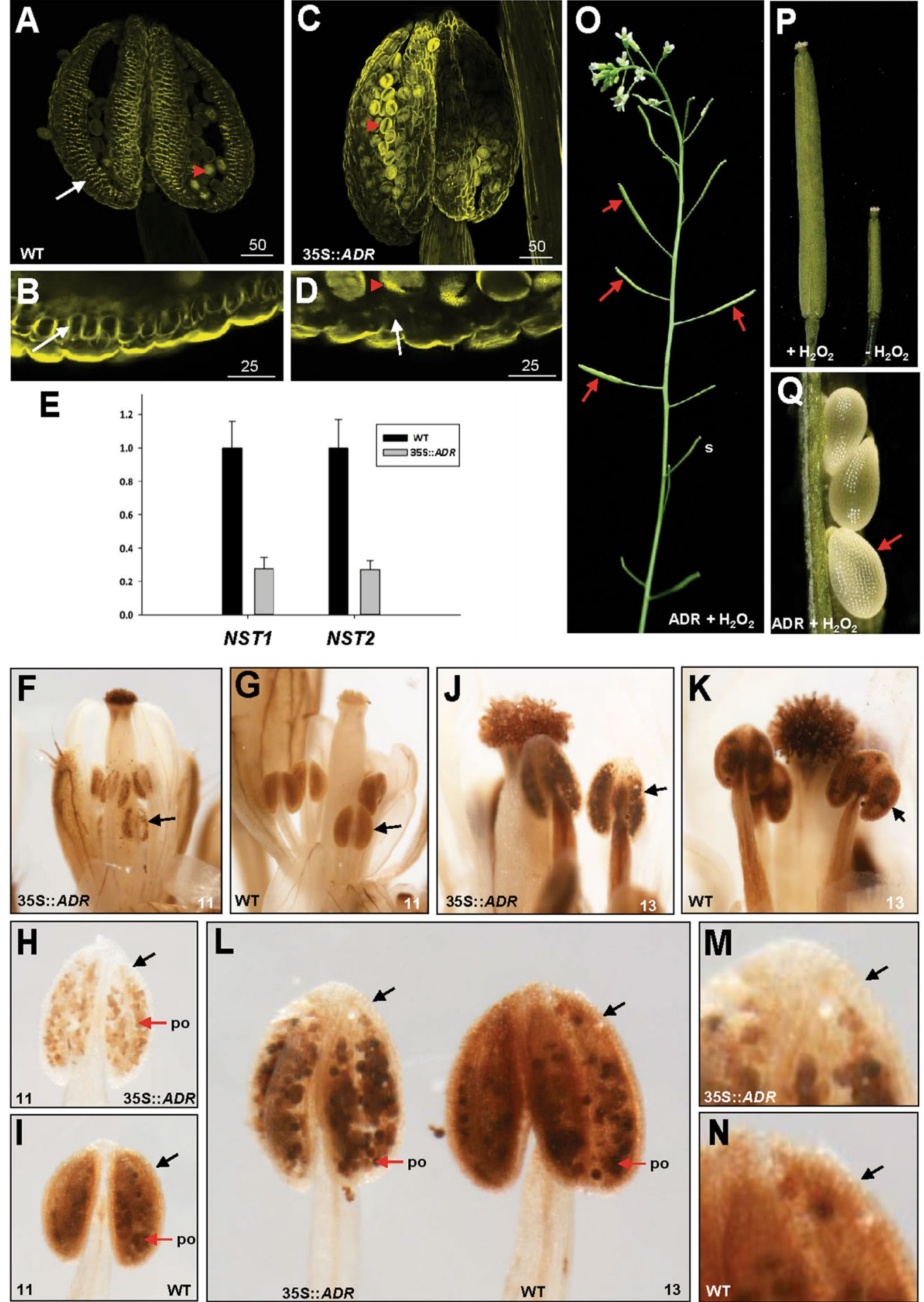

\section{(n)}

Figure 6. Lignin staining of anthers, NST1/NST2 expression, DAB staining in wild-type and 35S::ADR flowers and the phenotypic analysis of the $\mathrm{H}_{2} \mathrm{O}_{2}$-treated $35 \mathrm{~S}:: A D R$ flowers. (A-D) Anthers at stage 12 were stained with auramine $\mathrm{O}$ and observed by confocal microscopy ( $488 \mathrm{~nm}$ excitation/510-560 nm emission). Secondary thickening is visible in the endothecium (arrow) of the anthers of wild-type plants $(\mathbf{A}, \mathbf{B})$ but is absent in 35S::ADR plants (C,D). Red arrowheads indicate pollen grains. (B and $\mathbf{D}$ ) are close-up images of (A and C), respectively. (E) Detection of NST1/NST2 expression in 35S::ADR transgenic Arabidopsis plants. mRNA accumulation of NST1/NST2 was determined by real-time quantitative PCR. Total RNA was isolated from flowers of one wild-type (WT) plant and one 35S::ADR plant and used as templates. The transcript levels of NST1/NST2 were determined using three replicates and normalized against UBQ10. The NST1/NST2 expression level in $35 S:: A D R$ plants is presented relative to wild-type plants, which was set at 1 . Error bars represent the standard deviation. Each experiment was repeated twice with similar results. (F-I) At floral stage 11 , stronger DAB staining was observed in anther tissue (arrow) of wild-type flowers (G,I) than in 35S::ADR 
flowers $(\mathbf{F}, \mathbf{H}) .(\mathbf{H})$ is a close-up image for 35S::ADR anther whereas (I) is a close-up image for wild-type anther. Pollen (po) was stained similarly in $35 \mathrm{~S}:: A D R$ and wild-type flowers. (J-L) At floral stage 13, stronger DAB staining was observed in the anther tissue (arrowed) of wild-type flowers (K,L) than in 35S::ADR flowers (J,L). (L) is the close-up images for 35S::ADR (left) and wild-type anthers (right). Pollen (po) was stained similarly in 35S::ADR and wild-type flowers. (M,N) Close-up images for 35S::ADR (M) and wild-type anther tissue $(\mathbf{N})$ from $(\mathbf{L})$. Stronger DAB staining was observed in the anther tissue (arrowed) of wild-type (N) than in 35S::ADR (M) flowers. (O) 7 days after $1 \mathrm{mM} \mathrm{H}_{2} \mathrm{O}_{2}$ treatment, the $35 \mathrm{~S}$ :: $A D R$ flower developed a well-elongated silique (arrowed), whereas short siliques (s) developed without $\mathrm{H}_{2} \mathrm{O}_{2}$ treatment. (P) Close-up of a well-elongated silique $\left(\mathrm{H}_{2} \mathrm{O}_{2}\right.$ treatment; left) and a short silique (right) without $\mathrm{H}_{2} \mathrm{O}_{2}$ treatment from $(\mathbf{O})$. (Q) The $35 \mathrm{~S}:: A D R$ ovules developed into normal embryos (arrows) after $10 \mu \mathrm{M} \mathrm{H}_{2} \mathrm{O}_{2}$ treatment.

wild-type anther development (Fig. 6A,B ${ }^{6,7}$. In contrast, no secondary thickening or lignification was observed in the anther endothecium of 35S::ADR plants (Fig. 6C,D). This result indicates that the developmental processes of anther dehiscence in 35S::ADR plants is interrupted by the failure of lignification as well as secondary wall thickening in endothecial cells of the anthers.

The expression of NST1/2 that participate in lignin accumulation of anther secondary walls was down-regulated in 35S::ADR transgenic Arabidopsis. It has been previously reported that two NAC-like genes, NAC SECONDARY WALL THICKENING PROMOTING FACTOR 1 (NST1) and NST2, are involved in the regulation of male sterility in plants. Double mutants of $n s t 1 / n s t 2$ cause male sterility and have a similar anther-indehiscent phenotype ${ }^{18}$ as that of $35 S:: A D R$ plants. It has been reported that NST1 and NST2 regulate secondary wall thickening in various tissues, and anther dehiscence in the $n s t 1 / n s t 2$ double mutants is due to the loss of secondary wall thickening in the anther endothecium ${ }^{18}$.

It is also interesting to explore whether the ectopic expression of $A D R$ affects the expression of NST1/2 genes in transgenic plants and causes the alteration of anther dehiscence. Thus, the expression of these two genes was analyzed from the flowers of 35S::ADR transgenic plants by real-time quantitative RT-PCR analysis. The result indicated that the transcript levels of the NST1 and NST2 were significantly down-regulated in the flowers of $35 \mathrm{~S}:: A D R$ plants (Fig. 6E). This result indicates that altered anther dehiscence in 35S::ADR plants is correlated with the altered expression of NST1/2 that participate in the regulation of secondary wall thickening in anthers.

ROS accumulation was lower in 35S::ADR anthers than in wild-type anthers. It has been known that the lignification of the secondary wall thickening in endothecial cells of the anther depends on ROS level ${ }^{15}$. The peroxisome has been thought to be the major location of reactive oxygen species (ROS) scavenging in plant cells $^{31}$. Since the lignification of the endothecial cells of the 35S::ADR anthers is affected, it is possible that the $\mathrm{H}_{2} \mathrm{O}_{2}$ accumulation in $35 \mathrm{~S}:: A D R$ anthers is altered. To confirm whether ADR associates with the peroxisome and further affects ROS accumulation, endogenous $\mathrm{H}_{2} \mathrm{O}_{2}$, which is the major ROS form in plant cells, in 35S::ADR and wild-type anthers at different developmental stages was detected directly by $3^{\prime}, 3^{\prime}$-diaminobenzidine (DAB), which is oxidized by $\mathrm{H}_{2} \mathrm{O}_{2}$, generating a dark brown precipitate ${ }^{32-34}$. The results indicated that a significant reduction of $\mathrm{H}_{2} \mathrm{O}_{2}$ accumulation was observed in 35S::ADR anthers in mature flower buds (stage 11; Fig. 6F,H) than in wild-type anthers (Fig. 6G,I) as observed by the much lighter brown precipitate in anther tissues. A similar reduction of $\mathrm{H}_{2} \mathrm{O}_{2}$ accumulation was also observed in $35 \mathrm{~S}$ ::ADR anther tissue in mature flowers (stage 13; Fig. 6J,L,M) than in wild-type anthers (Fig. 6K,L,N). Pollen grains from both wild-type and 35S::ADR flowers showed a similar level of brown precipitate (Fig. 6H,I,L).

This result further supports the hypothesis that the developmental processes of anther dehiscence in 35S::ADR plants is interrupted by reduced ROS accumulation and the subsequent failure of lignification as well as secondary wall thickening in endothecial cells of the anthers.

External application of $\mathrm{H}_{2} \mathrm{O}_{2}$ rescued anther indehiscence in 35S::ADR flowers. To further investigate whether the supply of $\mathrm{H}_{2} \mathrm{O}_{2}$ affects anther indehiscence in $35 \mathrm{~S}:: A D R$ flowers, $1 \mathrm{mM} \mathrm{H}_{2} \mathrm{O}_{2}$ was externally applied to the bud clusters of the $35 \mathrm{~S}:: A D R$ plants. Similar to the development of wild-type flower, anther dehiscence and normal silique elongation (Fig. 6O,P) were observed in the $35 \mathrm{~S}:: A D R$ flowers 7 days after $\mathrm{H}_{2} \mathrm{O}_{2}$ treatment. Further analysis indicated that the ovules from $\mathrm{H}_{2} \mathrm{O}_{2}$-treated 35S::ADR flowers were able to develop into normal embryos (Fig. 6Q). In contrast, silique elongation was not observed in $\mathrm{H}_{2} \mathrm{O}_{2}$-untreated mock flowers throughout the flower development (Fig. 6O,P). This result confirmed that the indehiscent anther phenotype in $35 \mathrm{~S}:: A D R$ flowers is due to the reduction of the ROS accumulation and can be complimented by exogenous $\mathrm{H}_{2} \mathrm{O}_{2}$.

\section{Discussion}

In this study, the $A D R$ gene in Arabidopsis was functionally analyzed. Ectopic expression of $A D R$ caused indehiscent anthers and resulted in a male-sterile phenotype throughout flower development. Therefore, we proposed that the $A D R$ gene is functionally related to the regulatory process of anther dehiscence. This hypothesis was supported by the expression pattern of the $A D R$ gene in the anthers of the stamens during flower development. In ADR::GUS flowers, GUS activity was strongly detected in the anthers at early developmental stages but was significantly lower in mature flowers at late developmental stages. This pattern indicates the possibility that the function of the $A D R$ gene is to negatively regulate anther dehiscence during the early stages of flower development. Anther dehiscence occurred once ADR expression decreased after maturation. It is reasonable to conclude that the ectopic expression of $A D R$ in plants extends its suppression into the late stages of flower development and causes anther indehiscence throughout flower development. 


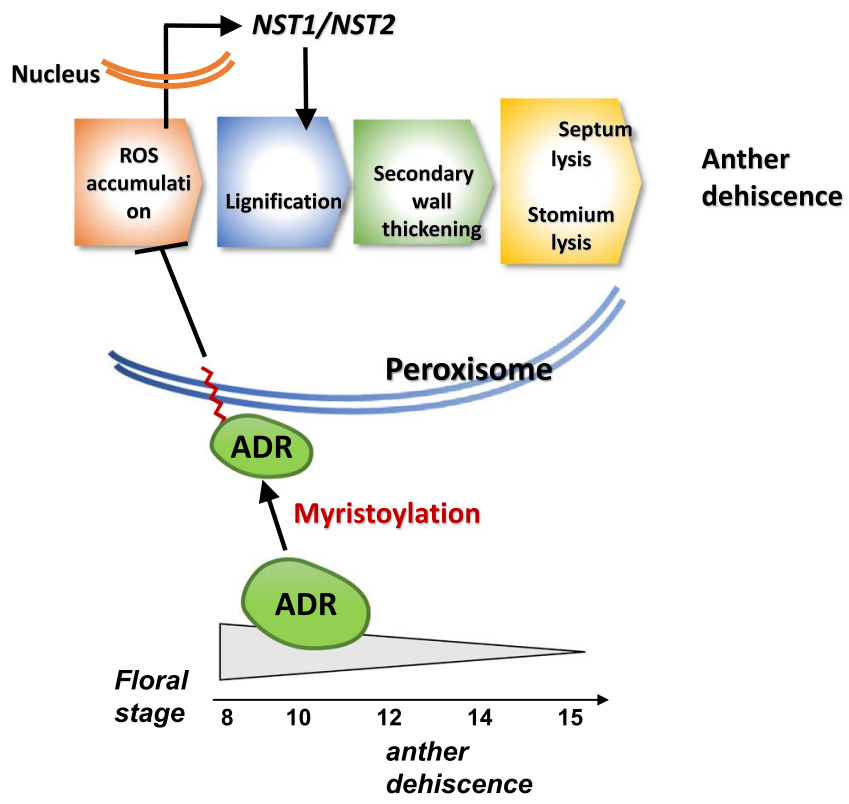

Figure 7. Model for the function of $A D R$ in regulating anther dehiscence in Arabidopsis. In wild-type Arabidopsis, $A D R$ is highly expressed in anthers during early anther development. The ADR protein is $\mathrm{N}$-myristoylated and targeted to the peroxisomal membrane to further suppress $(-1)$ the ROS accumulation, impedes lignification and down-regulates genes such as NST1/2 that participate in secondary wall thickening in endothecial cells of the anthers. This causes the inhibition of anther dehiscence during early flower development. During late flower development, a significant decrease in ADR expression causes an increase in ROS accumulation and lignification in the anthers and the up-regulation of NST1/NST2, resulting in anther dehiscence in wild-type flowers. In 35S::ADR plants, the ROS accumulation and lignification are suppressed by the high expression of $A D R$ during all stages of flower development. This suppression prevents anther dehiscence and the release of pollen throughout flower development. The gradient of $A D R$ activity is illustrated by the gradual reduction in the size of the gray bar $(\triangleright)$ during flower maturation.

The N-terminus of ADR is presumed to be myristoylated, and this myristoylation process is critical for its membrane association ${ }^{23}$. It has been reported that myristoylation alone is not sufficient to anchor a protein stably to a membrane; the $\mathrm{N}$-terminal basic residues contribute to protein membrane association via electrostatic interactions with acidic phospholipids ${ }^{26}$. The identification of several basic residues in the $\mathrm{N}$-terminus and a binding site for a peroxisomal targeting signal (PTS) in the middle of ADR supports the idea that it has a role in controlling anther dehiscence as a membrane-associated protein in the peroxisome. Clearly, this hypothesis was supported by the results of the transient expression experiment in which the ADR protein were associated with peroxisomes. These results support the assumption that myristoylation of ADR and its presence in the peroxisomes are important for its function to prevent anther dehiscence during the early stages of floral development (Fig. 7).

It is interesting to explore the exact role of $A D R$ in the negative regulation of anther dehiscence. The indehiscent anthers observed in 35S::ADR flowers were similar to those of plants with double mutations in two NAC-like genes, NST1 and NST2, which regulate secondary wall thickening in the anther endothecium ${ }^{18}$. Not surprisingly, no secondary thickening or lignification occurred in the anther endothecium of 35S::ADR plants. Furthermore, the expression of NST1 and NST2 was clearly down-regulated in 35S::ADR plants. Thus, these two genes are likely to function downstream and be negatively regulated by $A D R$.

The next question is how ADR functions and subsequently regulates secondary wall thickening in the anther endothecium. It is also known that lignin is the major compound involved in secondary wall thickening in anthers, and its polymerization is catalyzed by peroxidases that use $\mathrm{H}_{2} \mathrm{O}_{2}$ as a substrate ${ }^{10-13}$. Thus, ADR could possibly function to suppress lignification by decreasing $\mathrm{H}_{2} \mathrm{O}_{2}$ accumulation and disable secondary wall thickening in the endothecial cells of anthers. In this study, we found that $\mathrm{H}_{2} \mathrm{O}_{2}$ accumulation in $35 \mathrm{~S}:: A D R$ anther tissue is inhibited. This result strongly indicates that $A D R$ suppresses anther dehiscence in $35 S$ :: $A D R$ plants primarily due to the reduction in $\mathrm{H}_{2} \mathrm{O}_{2}$ accumulation and subsequent failure of both lignification and secondary wall thickening in the endothecial cells of the anther (Fig. 7). Following lignin polymerization, excess $\mathrm{H}_{2} \mathrm{O}_{2}$ can diffuse into the cytoplasm and regulate the expression of nuclear genes (Fig. 7), a process called retrograde signaling ${ }^{34-36}$. Thus, the reduction of $\mathrm{H}_{2} \mathrm{O}_{2}$ accumulation in $35 \mathrm{~S}:: A D R$ plants may suppress NST1/2 expression in the nucleus and result in the enhancement of the anther indehiscence phenotype, as observed in our results.

Our results reveal a possible model for the interaction of $A D R$ and ROS accumulation in regulating anther dehiscence in Arabidopsis, illustrated in Fig. 7. In wild-type Arabidopsis, the high level of ADR expression and the target of myristoylated ADR in anther peroxisomes during early stamen development results in the subsequent suppression of $\mathrm{H}_{2} \mathrm{O}_{2}$ accumulation, NST1/2 expression, lignification and secondary wall thickening in endothecial cells, thereby preventing early anther dehiscence. During late flower development, $A D R$ expression is reduced 
and no longer suppresses $\mathrm{H}_{2} \mathrm{O}_{2}$ production and the processes listed above. Thus, these processes are activated in the stamen, resulting in the initiation of anther dehiscence and the release of mature pollen. In 35S::ADR plants, the production of $\mathrm{H}_{2} \mathrm{O}_{2}$ and subsequent processes were suppressed due to the high level of $A D R$ expression at all stages of flower development. The suppression of these processes causes the subsequent failure of secondary wall thickening in the anther endothecial cells and results in anther indehiscence throughout flower development, similar to the phenotypes observed in $n s t 1 / 2$ double mutations.

In conclusion, we demonstrated that myristoylated ADR associates with the peroxisome and negatively regulates anther dehiscence by promoting ROS scavenging, ultimately affecting lignin polymerization and stomium rupture in Arabidopsis.

\section{Materials and Methods}

Plant materials and growth conditions. The T-DNA insertion mutants of ADR (SALK_072305) Arabidopsis seeds were obtained from the Arabidopsis Biological Resource Center, Ohio State University, Columbus, OH, USA. Arabidopsis seeds were sterilized and placed on agar plates containing 1/2 X Murashige \& Skoog medium ${ }^{37}$ at $4{ }^{\circ} \mathrm{C}$ for 2 days. The seedlings were then grown in growth chambers under long-day conditions (16-h light/8-h dark) at $22^{\circ} \mathrm{C}$ for 10 days before being transplanted to soil. The light intensity of the growth chambers was $150 \mu \mathrm{E} \mathrm{m}^{-2} \mathrm{~s}^{-1}$.

RNA isolation and RT-PCR analysis. Total RNA isolation from Arabidopsis plants for use in RT-PCR analysis was described previously ${ }^{38}$. Plant tissues were harvested, and the RNA was isolated using TRIzol Reagent (Invitrogen, USA). After being treated with DNase I (Promega), $2 \mu \mathrm{g}$ of total RNA was subjected to reverse transcription reaction using the IMPROM II reverse transcriptase (Invitrogen, USA) at $25^{\circ} \mathrm{C}$ for $5 \mathrm{~min}, 42^{\circ} \mathrm{C}$ for $1 \mathrm{~h}$ and $70^{\circ} \mathrm{C}$ for $15 \mathrm{~min}$. The resulting cDNA was used for PCR amplification with the gene-specific primers. The Arabidopsis ACTIN8 (ACT8) gene was used as internal controls. Sequences of the primers used are listed in Supplementary Table S1.

Cloning of the cDNA of ADR from Arabidopsis. ADR (At4g13540), which contains two exons and one intron, was identified on chromosome four. cDNA containing an open reading frame of $A D R$ was amplified by RT-PCR using the $5^{\prime}$ primer ADR-cDNA-For and the $3^{\prime}$ primer ADR-cDNA-Rev. The former contained the generated $\mathrm{XbaI}$ recognition site $\left(5^{\prime}-\mathrm{TCTAGA}-3^{\prime}\right)$, and the latter contained the generated KpnI recognition site $\left(5^{\prime}\right.$-GGTACC- $\left.3^{\prime}\right)$ to enable the cloning of $A D R$ cDNA. To generate the $A D R$-Gly fragment, cDNA containing an open reading frame of $A D R$ with the first two glycine codons removed was amplified by PCR using the $5^{\prime}$ primer ADR-dsc-dG-For and the $3^{\prime}$ primer ADR-cDNA-Rev. The former contained the generated Pst recognition site $\left(5^{\prime}-\mathrm{CTGCAG}-3^{\prime}\right)$ to enable the cloning of $A D R-G l y$ cDNA. Sequences of the primers are listed in Supplementary Table S1.

The amplified fragment containing the cDNA of the $A D R$ or $A D R-G l y$ was cloned into the linker region in the binary vector pEpyon-12K $\mathrm{K}^{39}$ (CHY Lab, Taichung, Taiwan) under the control of cauliflower mosaic virus (CaMV) $35 S$ promoter (35S::ADR and 35S::ADR-Gly) and used for further plant transformation.

ADR::GUS fusion construct. For the ADR::GUS construct, the ADR promoter $(1.6 \mathrm{~kb})$ was obtained by PCR amplification from the genomic DNA using the pADR-For and pADR-Rev primers and then cloned into pGEMT easy vector (Promega, Madison, WI, USA). The full-length promoter of ADR (1.6 kb) was then subcloned into the linker region before the $\beta$-glucuronidase (GUS) coding region in the binary vector pEpyon- $01 \mathrm{~K}^{39}$. The primers contained the generated PstI (5'-CTGCAG-3') recognition site and XbaI (5'-TCTAGA-3') recognition site to enable the cloning of the promoter. Sequences of the primers are listed in Supplementary Table S1.

Construction of the ADR + GFP, CAT3-mORG2 and MT-RK constructs. To generate the ADR fragment, cDNA containing an open reading frame of $A D R$ without the stop codon was amplified by PCR using the $5^{\prime}$ primer ADR-dsc-For and the $3^{\prime}$ primer ADR-dsc-Rev. The amplified ADR fragment was then cloned into the linker region in the binary vector pEpyon-32H (CHY Lab, Taichung, Taiwan) upstream of the GFP fragment to generate the $A D R+G F P$ construct, which were under the control of cauliflower mosaic virus (CaMV) $35 \mathrm{~S}$ promoter.

To generate the CAT3 fragment, cDNA containing an open reading frame of CAT3 without the stop codon was amplified by PCR using the $5^{\prime}$ primer CAT3-For and the $3^{\prime}$ primer CAT3-dsc-Rev. The amplified CAT3 fragment was cloned into the linker region in the binary vector pEpyon-34K (CHY Lab, Taichung, Taiwan) upstream of the mORANGE2 fragment to generate the CAT3-mORG2 construct, which was under the control of cauliflower mosaic virus (CaMV) 35S promoter. Sequences of the primers used are listed in Supplemental Table S1. Mitochondria fusion binary plasmid (CD3-991) which contained mitochondria marker fused with mCherry fluorescent protein was obtained from the ABRC (clone name: MT-RK) ${ }^{40}$.

Transient gene expression in leaf epidermal cells of Nicotiana benthamiana. Nicotiana benthamiana leaves were infiltrated with Agrobacterium strain C58C1 containing the pEpyon-32H vector carrying $A D R+G F P$ fragment, the pEpyon-34K vector carrying CAT3-mORG2 fragment, and MT-RFP using the methods described previously ${ }^{41}$. Infiltrated leaves were observed using a confocal microscope (Olympus FV1000). For ADR-GFP, excitation by $488 \mathrm{~nm}$ laser; and fluorescence was collected at $490-535 \mathrm{~nm}$. For CAT3-mORG2, excitation by $543 \mathrm{~nm}$ laser, and fluorescence was collected at $550-650 \mathrm{~nm}$. For MT-RK, excitation by $543 \mathrm{~nm}$ laser, and fluorescence was collected at 580-640 $\mathrm{nm}$. 
Real-time PCR analysis. For real-time quantitative PCR, the reaction was performed on an MJ Opticon system (MJ Research, Waltham, MA) using SYBR Green Real-Time PCR Master Mix (Toyobo Co., Ltd.). The amplification conditions were $95^{\circ} \mathrm{C}$ for 10 minutes followed by 40 cycles of amplification $\left(95^{\circ} \mathrm{C}\right.$ for 15 seconds, $58^{\circ} \mathrm{C}$ for 15 seconds, and $72^{\circ} \mathrm{C}$ for 30 seconds, followed by plate reading) and melting $\left(50-95^{\circ} \mathrm{C}\right.$, with plate readings every $1^{\circ} \mathrm{C}$ ). The sequences of the primers that were used for the real-time quantitative RT-PCR for $A D R$, NST1 and NST2 are listed in Supplementary Table S1. The Arabidopsis housekeeping gene UBQ10 was used as a normalization control with the primers RT-UBQ10-1 and RT-UBQ10-2. All of the experiments were repeated at least twice for reproducibility. The data were analyzed using Gene Expression Macro software (version 1.1,

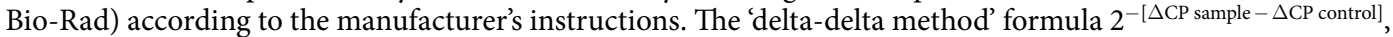
where 2 represents perfect PCR efficiency, was used to calculate the relative expression of the genes. To calculate the statistical significance, unpaired T-tests were used.

Plant transformation and transgenic plant analysis. Constructs in this study were introduced into Agrobacterium tumefaciens strain GV3101 and transformed into Arabidopsis plants using the floral dip method as described elsewhere ${ }^{42}$. Transformants that survived in the medium containing kanamycin $\left(50 \mu \mathrm{g} \mathrm{ml}^{-1}\right)$ were further verified by PCR and RT-PCR analyses.

Histochemical GUS assay. Histochemical staining was performed under the standard method described previously ${ }^{43,44}$.

Alexander's staining. For pollen analysis, pollen grains were mounted with Alexander's stain as previously described $^{30}$.

Scanning electron microscopy (SEM). Scanning electron microscopy was performed according to the methods described previously ${ }^{45-47}$. Various floral organs were fixed in $2 \%$ glutaraldehyde in $25 \mathrm{mM}$ sodium phosphate buffer ( $\mathrm{pH} 6.8$ ) at $4{ }^{\circ} \mathrm{C}$ overnight. After dehydration in a graded ethanol series, specimens were critical-point dried in liquid $\mathrm{CO}_{2}$. The dried materials were mounted and coated with gold-palladium in a JBS sputter-coater (model 5150). Specimens were examined with a field emission scanning electron microscope (JEOL JSM-6700F, Japan) with an accelerating voltage of $15 \mathrm{kV}$.

Lignin staining. For lignin analysis, fresh anthers were stained with $0.01 \%$ auramine $\mathrm{O}^{48}$ and $0.5 \mathrm{mg} \mathrm{ml}^{-1}$ Calcofluor white ${ }^{49}$ and observed using a confocal microscope (Olympus FV1000). The lignified cells were observed under $488 \mathrm{~nm}$ excitation/510-560 $\mathrm{nm}$ emission as described previously ${ }^{50}$.

Application of $\mathrm{H}_{2} \mathrm{O}_{2}$. For $\mathrm{H}_{2} \mathrm{O}_{2}$ complement experiment, $1 \mathrm{mM} \mathrm{H}_{2} \mathrm{O}_{2}$ solution containing $0.01 \%$ silwet L-77 was prepared and externally applied by dropping to the bud clusters of the $35 \mathrm{~S}:: A D R$ plants. The development of the silique for $\mathrm{H}_{2} \mathrm{O}_{2}$ treated flower buds was recoded and pictures were taken 10 days after treatment.

DAB staining. The $\mathrm{H}_{2} \mathrm{O}_{2}$ staining agent $\mathrm{DAB}$ (D5637, Sigma-Aldrich) was dissolved in water, after which the $\mathrm{pH}$ was adjusted to 3.8 with $\mathrm{KOH}$. Inflorescences with flowers were treated with $10 \mu \mathrm{M}$ DAB staining solution under vacuum for 4 hours. Samples were then incubated in $90 \%$ ethanol at $70^{\circ} \mathrm{C}$ for $10 \mathrm{~min}$ to remove chlorophyll. A dark brown color was visualized for $\mathrm{H}_{2} \mathrm{O}_{2}$ due to the oxidization of DAB.

\section{References}

1. Smyth, D. R., Bowman, J. L. \& Meyerowitz, E. M. Early flower development in Arabidopsis. Plant Cell 2, $755-767$ (1990).

2. Sanders, P. M. et al. Anther developmental defects in Arabidopsis thaliana male-sterile mutants. Sex Plant Reprod. 11, 297-322 (1999).

3. Dawson, J. et al. Characterization and genetic mapping of a mutation (ms35) which prevents anther dehiscence in Arabidopsis thaliana by affecting secondary wall thickening in the endothecium. New Phytol. 144, 213-222 (1999).

4. Scott, J. R., Spielman, M. \& Dickinson, H. G. Stamen structure and function. Plant Cell 16, S46-S60 (2004).

5. Wilson, Z. A., Song, J., Taylor, B. \& Yang, C. The final split: The regulation of anther dehiscence. J. Exp. Bot. 62, 1633-1649 (2011).

6. Cecchetti, V. et al. Auxin controls Arabidopsis anther dehiscence by regulating endothecium lignification and jasmonic acid biosynthesis. Plant J. 74, 411-422 (2013).

7. Yang, C. Y. et al. Arabidopsis MYB26/MALE STERILE35 regulates secondary thickening in the endothecium and is essential for anther dehiscence. Plant Cell 19, 534-548 (2007).

8. Keijzer, C. The processes of anther dehiscence and pollen dispersal. I. The opening mechanism of longitudinally dehiscing anthers. New Phytol. 105, 487-489 (1987).

9. Bonner, L. \& Dickinson, H. Anther dehiscence in Lycopersicon esculentum Mill. I. Structural aspects. New Phytol. 113, 97-115 (1989).

10. Kawasaki, T. et al. Cinnamoyl-CoA reductase, a key enzyme in lignin biosynthesis, is an effector of small GTPase Rac in defense signaling in rice. Proc. Natl. Acad. Sci. USA 103, 230-235 (2006).

11. Boerjan, W., Ralph, J. \& Baucher, M. Lignin biosynthesis. Annu. Rev. Plant Biol. 54, 519-546 (2003).

12. Ralph, J. et al. Lignins: natural polymers from oxidative coupling of 4-hydroxyphenylpropanoids. Phytochem. Rev. 3, 29-60 (2004).

13. Yoo, K. S. et al. Single cystathionine b-Synthase domain-containing proteins modulate development by regulating the thioredoxin system in Arabidopsis. Plant Cell 23, 3577-3594 (2011).

14. Liu, Q., Luo, L. \& Zheng, L. Lignins: Biosynthesis and Biological Functions in Plants. Int. J. Mol. Sci. 19(2), 335 (2018).

15. Villarreal, F. et al. Ectopic expression of mitochondrial gamma carbonic anhydrase 2 causes male sterility by anther indehiscence. Plant Mol. Biol. 70, 471-485 (2009).

16. Bienert, G. P., Schjoerring, J. K. \& Jahn, T. P. Lignins: Membrane transport of hydrogen peroxide. Biochimica et Biophysica Acta (BBA) - Biomembranes 1758(8), 994-1003 (2006).

17. Nyathi, Y. \& Baker, A. Plant peroxisomes as a source of signalling molecules. Biochim. Biophys. Acta. 1763(12), 1478-1495 (2006).

18. Mitsuda, N., Seki, M., Shinozaki, K. \& Ohme-Takagi, M. The NAC transcription factors NST1 and NST2 of Arabidopsis regulate secondary wall thickenings and are required for anther dehiscence. Plant Cell 17, 2993-3006 (2005).

19. Hu, J. et al. Plant peroxisomes: Biogenesis and function. Plant Cell 24, 2279-2303 (2012). 
20. Goto-Yamada, S., Mano, S. \& Nishimura, M. The Role of Peroxisomes in Plant Reproductive Processes. In Sawada, H., Inoue, N. \& Iwano, M. (eds) Sexual Reproduction in Animals and Plants. (Springer, Tokyo, 2014).

21. $\mathrm{Wu}$, J. et al. Spermidine oxidase-derived $\mathrm{H}_{2} \mathrm{O}_{2}$ regulates pollen plasma membrane hyperpolarization activated $\mathrm{Ca}^{2+}$-permeable channels and pollen tube growth. Plant J. 63, 1042-1053 (2010).

22. Li, X. R. et al. Arabidopsis DAYU/ABERRANT PEROXISOME MORPHOLOGY9 is a key regulator of peroxisome biogenesis and plays critical roles during pollen maturation and germination in planta. Plant Cell 26, 619-635 (2014).

23. Pierre, M. et al. N-myristoylation regulates the SnRK1 pathway in Arabidopsis. Plant Cell 19, 2804-2821 (2007).

24. Woodward, A. W. \& Bartel, B. The Arabidopsis peroxisomal targeting signal type 2 receptor PEX7 is necessary for peroxisome function and dependent on PEX5. Mol. Biol. Cell 16(2), 573-583 (2005).

25. Boutin, J. A. Myristoylation. Cell Signal 9, 15-35 (1997).

26. Bentham, M., Mazaleyrat, S. \& Harris, M. Role of myristoylation and N-terminal basic residues in membrane association of the human immunodeficiency virus type 1 Nef protein. J. Gen. Virol. 87, 563-571 (2006).

27. Zou, J. J. et al. Arabidopsis CALCIUM-DEPENDENT PROTEIN KINASE8 and CATALASE3 function in abscisic acid-mediated signaling and $\mathrm{H}_{2} \mathrm{O}_{2}$ homeostasis in stomatal guard cells under drought stress. Plant Cell 27, 1445-1460 (2015).

28. Wang, R. \& Brattain, M. G. The maximal size of protein to diffuse through the nuclear pore is larger than 60kDa. FEBS Lett. 581, $3164-3170$ (2014).

29. Zha, J., Weiler, S., Oh, K. J., Wei, M. C. \& Korsmeyer, S. J. Posttranslational N-Myristoylation of BID as a molecular switch for targeting mitochindria and apoptosis. Science 290, 1761-1765 (2000).

30. Alexander, M. P. Differential staining of aborted and non-aborted pollen. Stain Technol. 44, 117-122 (1969).

31. Costa, A. et al. $\mathrm{H}_{2} \mathrm{O}_{2}$ in plant peroxisomes: an in vivo analysis uncovers a Ca2+-dependent scavenging system. Plant J. 62, 760-772 (2010).

32. Bindschedler, L. V. et al. Peroxidase-dependent apoplastic oxidative burst in Arabidopsis required for pathogen resistance. Plant J. 47, 851-863 (2006).

33. Wu, A. et al. JUNGBRUNNEN1, a reactive oxygen species-responsive NAC transcription factor, regulates longevity in Arabidopsis. Plant Cell 24, 482-506 (2012).

34. Jung, K. W. et al. A Cystathionine- $\beta$-Synthase Domain-Containing Protein, CBSX2, Regulates Endothecial Secondary Cell Wall Thickening in Anther Development. Plant Cell Physiol. 54, 195-208 (2013).

35. Kimura, M., Yoshizumi, T., Manabe, K., Yamamoto, Y. Y. \& Matsui, M. Arabidopsis transcriptional regulation by light stress via hydrogen peroxide-dependent and -independent pathways. Genes Cells 6, 607-617 (2001).

36. Yabuta, Y., Maruta, T., Yoshimura, K., Ishikawa, T. \& Shigeoka, S. Two distinct redox signaling pathways for cytosolic APX induction under photooxidative stress. Plant Cell Physiol. 45, 1586-1594 (2004).

37. Murashige, T. \& Skoog, F. A revised medium for rapid growth and bioassays with tobacco tissue cultures. Physiol. Plant 15, 473-479 (1962).

38. Chen, W. H., Li, P. F., Chen, M. K., Lee, Y. I. \& Yang, C. H. FOREVER YOUNG FLOWER negatively regulates ethylene response DNA-binding factors (EDFs), by activating an Ethylene-Responsive Factor (ERF), to control Arabidopsis floral organ senescence and abscission. Plant Physiol. 168, 1666-1683 (2015).

39. Peng, Y. J. et al. A RING-Type E3 ligase controls anther dehiscence by activating the jasmonate biosynthetic pathway gene DEFECTIVE IN ANTHER DEHISCENCE1 in Arabidopsis. Plant J. 74, 310-327 (2013).

40. Nelson, B. K., Cai, X. \& Nebenführ, A. A multicolored set of in vivo organelle markers for co-localization studies in Arabidopsis and other plants. Plant J. 51, 1126-1136 (2007).

41. Wydro, M., Kozubek, E. \& Lehman, P. Optimization of transient Agrobacterium-mediated gene expression system in leaves of Nicotioana benthamiana. Acta Biochimica Polonica 53, 289-298 (2006).

42. Clough, S. J. \& Bent, A. F. Floral dip: a simplified method for Agrobacterium-mediated transformation of Arabidopsis thaliana. Plant J. 16, 735-743 (1998)

43. Jefferson, R. A., Kavanagh, T. A. \& Bevan, M. GUS fusions: $\beta$-glucuronidase as a sensitive and versatile gene fusion marker in higher plants. EMBO J. 6, 3901-3907 (1987).

44. Chou, M. L., Haung, M. D. \& Yang, C. H. EMF interact with late-flowering genes in regulating floral initiation genes during shoot development in Arabidopsis. Plant Cell Physiol. 42, 499-507 (2001).

45. Hsu, H. F. \& Yang, C. H. An orchid (Oncidium Gower Ramsey) AP3-like MADS gene regulates floral formation and initiation. Plant Cell Physiol. 43, 1198-1209 (2002).

46. Tzeng, T. Y. \& Yang, C. H. A MADS box gene from lily (Lilium longiflorum) is sufficient to generate dominant negative mutation by interacting with PISTILLATA (PI) in Arabidopsis thaliana. Plant Cell Physiol. 42, 1156-1168 (2001).

47. Chang, Y. Y. et al. Characterization of the possible roles for B class MADS box genes in regulation of perianth formation in orchid. Plant Physiol. 152, 837-853 (2010).

48. Pesquet, E. et al. Novel markers of xylogenesis in zinnia are differentially regulated by auxin and cytokinin. Plant Physiol. 139, 1821-1839 (2005).

49. Herth, W. \& Schnepf, E. The fluorochrome calcofluor white binds oriented to structural polysacharide fibrils. Protoplasma 105, $129-133(1980)$

50. Shih, C. F., Hsu, W. H., Peng, Y. J. \& Yang, C. H. The NAC-like gene ANTHER INDEHISCENCE FACTOR acts as a repressor that controls anther dehiscence by regulating genes in jasmonate biosynthesis pathway in Arabidopsis. J. Exp. Bot. 65, 621-639 (2014).

\section{Acknowledgements}

This work was supported by grants to C.-H.Y. from the Ministry of Science and Technology, Taiwan, ROC, Grant Number: NSC97-2313-B-005-019-MY3. This work was also financially supported (in part) by the Advanced Plant Biotechnology Center from The Featured Areas Research Center Program within the framework of the Higher Education Sprout Project by the Ministry of Education (MOE) in Taiwan.

\section{Author Contributions}

C.-H.Y. developed the overall strategy, designed experiments and coordinated the project. S.-Y.D. performed most of the experiments and analyzed the data. W.-H.H. performed Alexander's staining and lignin staining experiment. C.-H.Y. prepared and revised the manuscript.

\section{Additional Information}

Supplementary information accompanies this paper at https://doi.org/10.1038/s41598-019-41382-z.

Competing Interests: The authors declare no competing interests.

Publisher's note: Springer Nature remains neutral with regard to jurisdictional claims in published maps and institutional affiliations. 
(c) (i) Open Access This article is licensed under a Creative Commons Attribution 4.0 International License, which permits use, sharing, adaptation, distribution and reproduction in any medium or format, as long as you give appropriate credit to the original author(s) and the source, provide a link to the Creative Commons license, and indicate if changes were made. The images or other third party material in this article are included in the article's Creative Commons license, unless indicated otherwise in a credit line to the material. If material is not included in the article's Creative Commons license and your intended use is not permitted by statutory regulation or exceeds the permitted use, you will need to obtain permission directly from the copyright holder. To view a copy of this license, visit http://creativecommons.org/licenses/by/4.0/.

(C) The Author(s) 2019 